\title{
86736 - IDOSOS NA SALA DE AULA: UMA EXPERIÊNCIA DE INCLUSÃO DIGITAL
}

\author{
Pôster - Gerontologia
}

Vania B.M. Herédia / Vania B.M. Herédia / UCS; Verônica Bohm / Verônica Bohm / UCS

O estudo é resultado de pesquisa sobre aprendizagem digital de pessoas adultas e idosas de um programa de extensão, destinado a pessoas acima dos 50 anos de idade. O objetivo do estudo foi identificar as dificuldades enfrentadas pelo grupo na aprendizagem de novas tecnologias. $\mathrm{O}$ estudo é exploratório, de natureza quantitativa e qualitativa, e se propõe a investigar a aprendizagem digital dessa população no âmbito das novas tecnologias de informação e de comunicação, evidenciando interesses, mecanismos e obstáculos no processo. As referências teóricas usadas para sustentar o estudo se encontram nas obras de Nóvoa (2013), Stebbins (2008), Canário (2013), Jarvis (1987, 2015), Baltes (1987), Rabasco e Castellanos (2000) e Freire (2005). A construção dos dados empíricos se deu por intermédio de questionário estruturado, perguntas fechadas e abertas, aplicado com auxílio de ferramentas digitais: computadores, tabletes, smartphones e notebooks. A amostra construída por conveniência e intencionalidade (PEREIRA, 1995) foi definida por critérios previamente estabelecidos, ou seja, participar das oficinas sobre uso de tecnologias digitais, aceitar fazer parte da pesquisa, assinar o termo de consentimento livre. Os resultados parciais da pesquisa sinalizam um universo de aprendizagem digital potencializado fora da escola, porém na sala de aula. Os resultados mostram que os alunos registram a importância do professor para que aconteça o processo. Precisam também de exemplos e de explicações repetitivas para entender como se dá o uso das tecnologias. Além da experiência, registram que precisam anotar os passos para o uso de aplicativos. Vêm o processo como positivo já que proporciona integração com a família, amigos, parentes e também com a vida social. A pesquisa contribui para a inclusão de idosos por meio do conhecimento e uso de ferramentas e aplicativos. 